\title{
Supporting Accessibility in Higher Education Information Systems
}

\author{
Reis, A. ${ }^{1}$, Barroso, J. ${ }^{2}$, Gonçalves, R. ${ }^{2}$ \\ ${ }^{1}$ University of Trás-os-Montes e Alto Douro, Vila Real, Portugal \\ ars@utad.pt \\ ${ }^{2}$ INESC TEC (formerly INESC Porto) and University of Trás-os-Montes e \\ Alto Douro, Vila Real, Portugal \\ \{jbarroso, ramiro\}@utad.pt
}

\begin{abstract}
Higher education institutions (HEI) and students are highly dependent of information systems, implemented as web applications. Students must be able to access this applications, thought accessible web interfaces, in order to perform their academic activities. This paper presents an overview of a typical set of web applications used by students and the main concerns regarding accessibility compliance. The analysis was conducted using the systems at the University of Trásos-Montes e Alto Douro.
\end{abstract}

Keywords: Higher education institutions; Accessibility; W3C; Moodle; DSpace.

\section{Introduction}

Higher Education is a complex business, highly supported by Information Technology and Information Systems. Some of these information systems have web interfaces that enable students to access faculty services that, in some cases, were previously available as human interactions. The electronic interface, mainly the web, is now the default interface for accessing faculty services and, in some cases, the human infrastructure was restructured and is non-existent, leaving the electronic interface as the only interface. In this scenario, the electronic interface must be accessible by all students with no exception [1].

Higher education students are a special set of the population in terms of age and intellectual capability. Most information systems and software packages used in HEI are well typified in terms of business model and software implementation, so in addition to applying the common standards for accessibility, it's interesting to analyze this population and the information systems used at the university in greater detail. Another interesting particularity of HEI is the fact that teachers are content creators and sometimes class designers with different perceptions of the concept of accessibility and the role they play on assuring that same accessibility.

adfa, p. 1, 2011.

(C) Springer-Verlag Berlin Heidelberg 2011 
In this paper we follow a simple three steps method:

1. Characterize a typical set of information systems used in higher education institutions, of which the University of Trás-os-Montes e Alto Douro (UTAD) is well representative, as well as a user population, in regard to special accessibilities needs. In this case, the UTAD students.

2. Analyze the information systems [2], [3], regarding their compliance to W3C standards.

3. Conclude on the degree of accessibility provided by the university electronic services available to students and on some recommendations on how to effectively act to ensure accessibility.

\subsection{Web Accessibility}

Web accessibility can be defined as a practice of design, develop and edit web sites usable by all people without regard for their level of ability or disability, thus, granting equal access to information and functionality has normal people would have [4]. According to Jim Thatcher and Shaw Henry, web accessibility goal is to provide people with disability, the ability to perceive, understand, navigate and interact with the Web, including visual, hearing, physical, cognitive, speech or neurological impairments [5], [6].

\subsection{Student Population}

The Portuguese National Institute of Statistics (INE) developed a demographic study, in 2002, about the Portuguese population, regarding disabilities. According to this study, there were 634.000 Portuguese citizens with some kind of disability. This number accounts for about $6 \%$ of the country population, of about 10 million people [7].

The student's population of UTAD consists of about 7.000 students. According to the national percentage of citizen with disability, of $6 \%$, there should be about 420 students with some kind of special access need.

At registration, each student is asked to voluntarily declare any disabilities. The sole purpose of this declaration is to provide proper access and support for a normal student's life on campus. Unfortunately a large number of students with light disabilities chooses not to declare them.

\subsection{Information Systems in Higher Education Institutions}

In Higher Education Institutions (HEI) there is a set of information systems, used by students that are implemented by distinct software systems. These systems are characterized by their purpose and sometimes by their proprietary within the institutional organics.

A well representative set can be found at the University of Trás-os-Montes e Alto Douro (UTAD) as described in the following topics. 


\section{Scientific Repository}

The scientific repository purpose is to archive the documents related to research activities of the institution, including, articles, book chapter, thesis, etc. This system is a key element of the open access movement and institutional policies.

At UTAD the software package used is DSPACE [8], one of the most popular software packages built for this specific purpose.

\section{Elearning}

The elearning component purpose is to provide support for the teaching and learning activities. Teachers and students can manage content, activities and administrative tasks on this platforms. Although designated as "elearning", most times it is used for general pedagogical class management, also including b-leaning and traditional learning. At UTAD the software package used is Moodle [9].

\section{Library}

The library component purpose is to provide management support for the HEI library. It is used by the library staff for their management activities and it is used by students when interacting with the library services, such as, book requesting, catalog search, etc.

UTAD uses the Porbase software package [10], develop and distributed by the Portuguese National Library and widely used in Portuguese libraries. The student interaction with this component is fairly low and it's mostly used by library staff.

\section{Student Portal}

The student portal component is a web portal dedicated to provide information and services, related to the students' academic life, such as: course registration; fees payment; class scheduling; student grades, etc. It is used by all students and professors, on a daily basis and is one the most important components for the faculty regular activities. It is also used by some non-teaching staff. In some institutions, this component is integrated with the eleaning component.

At UTAD this portal is an in-house development project, named SIDE, using LAMP (Linux, Apache, Mysql and PHP), that implements the business model processes related to students, teachers, learning, teaching and administration. The SIDE Portal has a broad spectrum of usage and is tailored to meet the students and teachers information needs. Accessibility is a most important issue in this portal, as any student failing to access SIDE's information will not be able to execute his daily activities.

\section{Institutional Portal}

This component is the HEI web portal and its main purpose is to act has a communication channel from the HEI to the general public. Some parts of this portal are focused on the HEI business interests, such as, attracting students, publicizing research achievements, etc. 
At UTAD the portal is implemented using the Microsoft sharepoint 2010 platform as a web site content manager.

\begin{tabular}{|l|l|}
\hline Purpose & System \\
\hline Scientific repository & DSpace \\
\hline E-learning & Moodle \\
\hline Learning and student management & SIDE \\
\hline Library & Porbase \\
\hline General information & Website \\
\hline
\end{tabular}

Table 1. Systems used by students and their purposes

\section{Accessibility Concerns}

For this analysis, the systems, previously described, were grouped in two. The first include Moodle and DSpace; the second includes the in-house developed web portals.

\subsection{Moodle and DSpace}

The tests performed with Total Validator [11] were somehow ambiguous, as it is difficult to separate the pure software platform from the usage practice made by administrators, content creators and external web developers. In a strict sense, we didn't found a single point of total inaccessibility in this platforms, although some had to be tackled by the user.

As an example, in moodle, if the user uses a screen-reader, it will have to turn off the HTML editor on the user profile. As a software platform, moodle has a configuration option for the administrator and the user to choose an external editor. So although there is a latent accessibility problem the software has the necessary configuration options to overcome the problem. In this scenario, it is the administrator practice that dictates the accessibility.

In another example, the teacher role, as a content creator, is determinant on accessibility: if the teacher decides for a poor choice of colors, such as, pale green text over a yellow background; not to write proper alt-text for images; upload video and audio without proper transcript; etc. On this example, the content will not be accessible at all and accessibility will not be platform dependent.

\subsection{Student Portal and Institutional Portal}

These portals were developed in-house. The student portal is based on a LAMP infrastructure and the institutional portal is based on a sharepoint platform. On the student portal it is the developers responsibly to ensure and enforce accessibility. The design does not allow for administrator or user configuration, capable of changing accessibility. As previously stated, this portal is an in-house project and it is of most importance for the university daily life. The user interface is very simple in order to ensure 
user access and compatibility across browser and hardware platforms. UTAD is the only Portuguese university with a graduation on Accessibility, so the university most important web application is always under scrutiny regarding its accessibility compliance and usability [12].

On the institutional portal, the sharepoint 2010 platform is well documented as a platform for achieving accessibility [13], and it the template designer and developer responsibility to ensure an accessible interface.

\section{Conclusion}

The analysis has shown that the three platforms in use (moodle, dspace and sharepoint) didn't presented intrinsic accessibilities issues. The platforms are generic and flexible enough and it is up to the developers and administrators to ensure proper development and configuration practices. In the moodle case, it also the teacher role that must follow good accessibility practices. Teachers and administrators are a large group of people and a strategy should be designed to ensure the desire accessibility compliance. In such a large group, the correct practice should evolve to a cultural sustainable practice.

In the web portals group it was shown that the accessibly compliance depends solely on the designers and developers practice. Thus it can be predetermined has a design and implementation requirement, which can also be tested prior to the system acceptance and deployment. In the SIDE portal, beside accessibility, usability is also an issue and the design options were taken to accommodate both concepts together [14] [15].

\section{$4 \quad$ References}

1. Accessibility vs. Usability vs. W3C Web "Standards", Accessibility and Usability at Pen State. Accessed on February 2013. Available at: http://accessibility.psu.edu/usability.

2. FREIRE, André Pimenta ; FORTES, R. P. M. ; TURINE, M. A. S. ; PAIVA, Debora Maria Barroso . An Evaluation of Web Accessibility Metrics based on their Attributes. In: SIGDOC 2008, 2008, Lisboa - Portugal. Proceedings of he 26th ACM International Conference on Design of Communication. New York : ACM Press, 2008. v. 1. p. 73-80.

3. Evaluating Accessibility, W3C Web Accessibility initiative, http://www.w3.org/WAI/eval/Overview.html.

4. Yonaitis, R. (2002). Understanding Accessibility: A Guide to Achieving Compliance on Web Sites and Intranets. New Hampshire: HiSoftware.

5. Thatcher et al, "Constructing accessible web sites". Available at http://tocs.ulb.tu-darmstadt.de/202240762.pdf.

6. Ramiro Gonçalves, José Martins, Jorge Pereira, Henrique Mamede (2010). Portuguese Web Accessibility in Electronic Public Procurement Platforms. In Information Systems and Technologies (CISTI), 2010 5th Iberian Conference on. 16-19 June 2010.

7. INE, 2002. Censos 2001 - População residente com deficiência Segundo o grau de incapacidade e sexo.

8. DSpace project, http://www.dspace.org. 
9. Moodle project, http://www.moodle.org.

10. Porbase project, http://porbase5.mind.pt.

11. Total Validator, 2012. Accessed on December 2012. Available at: http://www.totalvalidator.com/.

12. Guide for developing usable web sites. Accessed December 2012. Available at: http://www.usability.gov/ .

13. Fleming, Ray (2012), Achieving Accessibility in SharePoint 2010. Accessed February 2013. Available at: http://blogs.msdn.com/b/education/archive/2012/02/28/achieving-accessibility-in-sharepoint-2010.aspx

14. Web Accessibility and Usability Working Together. Accessed on February 2013. Available at: http://www.w3.org/WAI/intro/usable.

15. Roe, Patrick (2001), "Bridging the Gap", Access to telecommunications for all people. Suíça: Comissão Europeia. 